\title{
Establishment and validation of prognostic nomograms integrating histopathological features in patients with invasive endocervical adenocarcinoma
}

\section{Li-Li Liu ( $D$ liulil@sysucc.org.cn )}

Sun Yat-sen University Cancer Center https://orcid.org/0000-0002-4347-2038

Shu-Lin Chen

Sun Yat-sen University Cancer Center

Xia Yang

Sun Yat-sen University Cancer Center

Yue Li

Sun Yat-sen University Cancer Center

Shi-Wen Zhang

Sun Yat-sen University Cancer Center

Yan-Lin Wen

Sun Yat-sen University Cancer Center

Rong-Zhen Luo

Sun Yat-sen University Cancer Center

Primary research

Keywords: Histological features, Invasive endocervical adenocarcinoma, LASSO-Cox regression model, Prognosis

Posted Date: December 10th, 2020

DOl: https://doi.org/10.21203/rs.3.rs-123003/v1

License: (9) This work is licensed under a Creative Commons Attribution 4.0 International License. Read Full License 


\section{Abstract \\ Background}

To develop and verify pathological models using pathological features basing on hematoxylin and eosin $(\mathrm{H} \& \mathrm{E})$ images to predict postoperative survival in patients with invasive endocervical adenocarcinoma (ECA).

\section{Method:}

There were 289 patients with ECA classified into training and validation cohorts. A histological signature was produced in 191 patients and verified in the validation group. Histological models combining the histological features were built. They showed increased value compared to the conventional model in terms of individualized prognosis estimation.

\section{Results}

Our model included five selected histological characteristics and was significantly related to overall survival (OS). In the training cohort, it had AUC values of 0.862 and 0.955 , respectively, for predicting 3and 5-year survival; in the validation cohort, the equivalent values were 0.891 and 0.801 . In the training cohort, it showed better OS evaluation ( $\mathrm{C}$-index: $0.832 ; 95 \%$ confidence interval $[\mathrm{Cl}]=0.751-0.913$ ) than both the FIGO staging system (C-index: $0.648 ; 95 \% \mathrm{Cl}=0.542-0.753$ ) and treatment (C-index: 0.687; 95\% $\mathrm{Cl}=0.605-0.769$ ), with advanced efficiency for classifying survival outcomes. In both cohorts, a risk stratification system was built that could precisely stratify patients with stage I and II ECA into high-risk and low-risk subpopulations with significantly different prognoses.

\section{Conclusion}

Our nomogram with five histological signatures had better accuracy in the prediction of OS in patients with ECA. This may contribute to the development of precision medicine in such patients.

\section{Introduction}

Endocervical adenocarcinoma (ECA) comprises approximately $25 \%$ of cervical cancers. It is much more heterogeneous than other types of cervical tumors, with around $15 \%$ of cases being unrelated to human papillomavirus (HPV) infection. ECA has a higher prevalence than squamous cell carcinoma because it is difficult to detect glandular lesions using cytological screening[1]. According to the International Endocervical Adenocarcinoma Criteria and Classification (IECC), ECA is categorized into HPV-associated (HPVA) and non-HPV-associated (NHPVA) types. Although most cases of ECA are associated with HPV infection, NHPVA is challenging to diagnose and tends to be aggressive[2-6]. Furthermore, International 
Federation of Gynecology and Obstetrics (FIGO) stage is the most critical parameter for determining treatment and prognosis, but significant heterogeneities in clinical prognosis occur among patients with ECA who show similar FIGO stage. Therefore, to improve prognosis in patients with ECAs, researchers must ascertain the substantial prognostic determinants.

ECAs are classified based on descriptive morphological characteristics, particularly cytoplasmic features[7]. However, ECAs cannot easily be categorized using the 2014 World Health Organization classification because they are defined based on empirical observation, rather than on clinical or biological features[7]. In our own studies, we have used the IECC classification for histological typing. Previous studies have identified several pathological variables with prognostic value in ECA, namely tumor size, depth of invasion (DOI), lymphovascular invasion (LVI), and lymph node metastasis (LNM) [8, 9]. Therefore, combined analysis of histological features is the most promising approach to improving clinical management. Previous studies have shown that this histological model is correlated with outcomes in patients with ECA. However, to our knowledge, no strategy has been developed that uses histological signatures to predict outcome.

In the present study, we generated and verified a histological feature-based histological model to predict outcomes. This histological model may accurately stratify patients with ECA into high- and low-risk groups.

\section{Materials And Methods \\ Patients and samples}

In the present retrospective study, we enrolled 289 patients with histologically confirmed ECA who had been treated at the Sun Yat-sen University Cancer Center between January 2010 and December 2014. Patients were enrolled when (1) they had been diagnosed with primary ECA, and (2) they had complete clinical data available. The exclusion criteria were as follows: (1) systemic metastasis at diagnosis, (2) co-existing malignancies, (3) history of anti-cancer therapy. Patients were classified into either the training group $(n=200)$ or the validation group $(n=89)$. The last follow-up was conducted in June 2020 . The Hospital Ethics Committee at the Sun Yat-sen University Cancer Center, China approved this study. The critical raw data associated with this article have been uploaded onto the Research Data Deposit public platform (www.researchdata.org.cn), with the following RDD approval number: RDD2020001505.

\section{Histologic features}

All slides were evaluated by histologists who had no knowledge of the corresponding patient information. In accordance with the new pathogenetic classification of the IECC, ECA was classified into HPVA and NHPVA histological types[10]. In all samples, the invasive patterns of the tumors were categorized as $A, B$, or $\mathrm{C}[11-14]$. The following features were evaluated: nuclear grade, tumor cell necrotic debris, mitosis/10 high-power fields (HPF), tumor giant cells/10 HPF, LVI, tumoral tumor-infiltrating lymphocytes (TILs), stromal TILs, differentiation, DOI, stromal invasion, nerve invasion, endometriosis invasion, LNM, 
extranodal involvement, and parametrium invasion. Tumor cell necrotic debris was classified as focal, moderate, or extensive. Nuclear grade was classified as previously reported[15]. Mitosis was calculated in 10 high power fields (HPF), as were tumor giant cells, which were categorized as either multi-nucleated tumor giant cells or single giant nuclear cells, with a nucleus 3-4 times bigger than the surrounding tumor nuclei. These cells are usually identified using low power (4区) or intermediate power (10区) microscopy. Following a standardized method, TILs were evaluated on hematoxylin and eosin (H\&E)stained slides to provide a percentage score for stromal and intratumoral compartments, as described previously[16]. The H\&E images of these features are shown in Supplementary Figs. 1 and 2.

\section{Construction and validation of the nomogram}

In the construction of the nomogram, we combined the following clinical variables and histological factors as prognostic characteristics: age, menopause, oral contraceptive use, chief complaint, histological type, FIGO stage, tumor size, differentiation, growth pattern, nuclear grade, tumor cells necrotic debris, mitosis/10HPF, tumor giant cells/10HPF, tumoral TILs, stromal TILs, LVI, DOI, stromal invasion, nerve invasion, endometrial invasion, LNM, extranodal involvement, parametrium invasion, and treatment. We used the least absolute shrinkage and selection operator (LASSO) regression with 10-fold cross-validation to choose the most useful predictive markers and create nomograms of overall survival (OS) from the training cohort.

\section{Statistical Analysis}

We used IBM SPSS Statistical software version 19.0 (IBM Corp., Chicago, IL, USA) and R version 3.4.0 (http://www. R-project.org/) for statistical analyses. Survival curves were conducted using the KaplanMeier approach.

\section{Results}

\section{Patient characteristics and survival}

The patients' clinicopathological features are listed in Table 1. No differences were observed in terms of age, therapeutic data (chemotherapy with or without radiotherapy), oral contraceptive usage, chief complaint, histological type, tumor size, differentiation, growth pattern, nuclear grade, tumor cells necrotic debris, mitosis/10HPF, giant cells/10HPF, tumoral TILs, stromal TILs, LVI, DOI, stromal invasion, nerve invasion, LNM, parametrium invasion, or FIGO stage. In the training and validation groups, the median follow-up periods were 59.4 months (range: 3.6-124.5 months) and 67.4 months (range: 1.5122.7 months). Moreover, the $1-, 3$-, and 5-year OS rates were $97.9 \%, 92.6 \%, 89.0 \%$, respectively, in the training group and $96.9 \%, 91.8 \%, 89.8 \%$, respectively in the validation groups. 
Table 1

Patient demographics and clinical charateristics in the training and validation cohorts.

\begin{tabular}{|c|c|c|c|}
\hline \multirow[t]{2}{*}{ Characteristic } & \multirow{2}{*}{$\begin{array}{l}\text { All patients } \\
\text { No. (\%) }\end{array}$} & \multirow{2}{*}{$\begin{array}{l}\text { Training cohort } \\
\text { No. (\%) }\end{array}$} & \multirow{2}{*}{$\begin{array}{l}\text { Validation cohort } \\
\text { No. (\%) }\end{array}$} \\
\hline & & & \\
\hline Total & 289 & 191 & 98 \\
\hline $\operatorname{Age}(y)^{*}$ & $45(40-52)$ & $45(40-51)$ & $45(40.8-52)$ \\
\hline \multicolumn{4}{|l|}{ Menopause } \\
\hline No & $222(76.8 \%)$ & $148(77.5 \%)$ & $74(75.5 \%)$ \\
\hline Yes & $67(23.2 \%)$ & $43(22.5 \%)$ & $24(24.5 \%)$ \\
\hline \multicolumn{4}{|l|}{ OCP usage } \\
\hline No & $282(97.6 \%)$ & $184(96.3 \%)$ & $98(100 \%)$ \\
\hline Yes & $7(2.4 \%)$ & $7(3.7 \%)$ & $0(0.0 \%)$ \\
\hline \multicolumn{4}{|l|}{ Main clinical finding } \\
\hline Vaginal bleeding & $220(76.1 \%)$ & $136(71.2 \%)$ & $84(85.7 \%)$ \\
\hline Mucoid discharge & $15(5.2 \%)$ & $14(7.3 \%)$ & $1(1.0 \%)$ \\
\hline Other & $54(18.7 \%)$ & $41(21.5 \%)$ & $13(13.3 \%)$ \\
\hline \multicolumn{4}{|l|}{ Histological type } \\
\hline HPVA & $27(9.3 \%)$ & $20(10.5 \%)$ & $7(7.1 \%)$ \\
\hline NHPVA & $262(90.7 \%)$ & $171(89.5 \%)$ & $91(92.9 \%)$ \\
\hline \multicolumn{4}{|l|}{ FIGO stage } \\
\hline I & $205(70.9 \%)$ & $131(68.6 \%)$ & $74(75.5 \%)$ \\
\hline II & $72(24.9 \%)$ & $51(26.7 \%)$ & $21(21.4 \%)$ \\
\hline III & $9(3.1 \%)$ & $6(3.1 \%)$ & $3(3.1 \%)$ \\
\hline IV & $3(1.6 \%)$ & $3(1.6 \%)$ & $0(0.0 \%)$ \\
\hline Tumor size $(\mathrm{cm}) *$ & $3(2-4)$ & $3(2-4)$ & $2.5(2.0-3.5)$ \\
\hline \multicolumn{4}{|l|}{ Differentiation } \\
\hline Good & $12(4.2 \%)$ & $9(4.7 \%)$ & $3(3.1 \%)$ \\
\hline Moderate & $156(54.0 \%)$ & $107(56.0 \%)$ & $49(50.0 \%)$ \\
\hline Poor & $121(41.8 \%)$ & $75(39.3 \%)$ & $46(46.9 \%)$ \\
\hline
\end{tabular}




\begin{tabular}{|c|c|c|c|}
\hline \multirow[t]{2}{*}{ Characteristic } & All patients & Training cohort & Validation cohort \\
\hline & No. (\%) & No. (\%) & No. (\%) \\
\hline \multicolumn{4}{|l|}{ Growth pattern } \\
\hline A & $26(9.0 \%)$ & $17(8.9 \%)$ & $9(9.2 \%)$ \\
\hline B & $34(11.8 \%)$ & $20(14.3 \%)$ & $14(14.3 \%)$ \\
\hline C & $229(79.2 \%)$ & $154(80.6 \%)$ & $75(76.5 \%)$ \\
\hline \multicolumn{4}{|l|}{ Nuclear grade } \\
\hline 1 & $38(13.1 \%)$ & $29(15.2 \%)$ & $9(9.2 \%)$ \\
\hline 2 & $153(52.9 \%)$ & $96(50.3 \%)$ & $57(58.2 \%)$ \\
\hline 3 & $98(33.9 \%)$ & $66(34.6 \%)$ & $32(32.7 \%)$ \\
\hline \multicolumn{4}{|l|}{ Tumor cell necrotic debris } \\
\hline Focal & $185(64.0 \%)$ & $121(63.4 \%)$ & $64(65.3 \%)$ \\
\hline Moderate & $55(19.0 \%)$ & $43(22.5 \%)$ & $12(12.2 \%)$ \\
\hline Extensive & $49(17.0 \%)$ & $27(14.1 \%)$ & $22(22.4 \%)$ \\
\hline Mitosis/10HPF* & $31(16-50)$ & $31(15-50)$ & $30(17.8-48.5)$ \\
\hline Number of tumor giant cells/10HPF* & $0(0-0)$ & $0(0-0)$ & $0(0-0)$ \\
\hline \multicolumn{4}{|l|}{ LVI } \\
\hline None & $200(69.2 \%)$ & $127(66.5 \%)$ & $73(74.5 \%)$ \\
\hline Focal & $56(19.4 \%)$ & $42(22.0 \%)$ & $14(14.3 \%)$ \\
\hline Moderate & $18(6.2 \%)$ & $10(5.2 \%)$ & $8(8.2 \%)$ \\
\hline Extensive & $15(5.2 \%)$ & $12(6.3 \%)$ & $3(3.1 \%)$ \\
\hline Tumoral TILs (\%) * & $1(1-1)$ & $1(1-1)$ & $1(1-1)$ \\
\hline Stromal TILs (\%) * & $20(10-50)$ & $20(10-50)$ & $20(10-50)$ \\
\hline Depth of invasion (mm)* & $12(8-16)$ & $12(8-17)$ & $12.5(7-16)$ \\
\hline \multicolumn{4}{|l|}{ Cervical stromal invasion } \\
\hline Inner $1 / 3$ & 77 (26.6\%) & $49(25.7 \%)$ & $28(28.6 \%)$ \\
\hline Middle 1/3 & $91(31.5 \%)$ & $58(30.4 \%)$ & $33(33.7 \%)$ \\
\hline Outer $1 / 3$ & 121 (41.9\%) & $84(44.0 \%)$ & $37(37.8 \%)$ \\
\hline
\end{tabular}




\begin{tabular}{|c|c|c|c|}
\hline \multirow[t]{2}{*}{ Characteristic } & All patients & Training cohort & Validation cohort \\
\hline & No. (\%) & No. (\%) & No. (\%) \\
\hline \multicolumn{4}{|l|}{ Nerve invasion } \\
\hline No & $262(90.7 \%)$ & $173(90.6 \%)$ & $83(90.8 \%)$ \\
\hline Yes & $27(9.3 \%)$ & $18(9.4 \%)$ & $9(9.2 \%)$ \\
\hline \multicolumn{4}{|l|}{ Endometriosis invasion } \\
\hline No & $232(80.3 \%)$ & $145(75.9 \%)$ & $87(88.8 \%)$ \\
\hline Yes & $57(19.7 \%)$ & $46(24.1 \%)$ & $11(11.2 \%)$ \\
\hline \multicolumn{4}{|l|}{ Lymph node metastasis } \\
\hline No & $225(77.9 \%)$ & $145(75.9 \%)$ & $80(81.6 \%)$ \\
\hline Yes & $64(22.1 \%)$ & $46(24.1 \%)$ & $18(18.4 \%)$ \\
\hline \multicolumn{4}{|l|}{ Extra nodal involvement } \\
\hline No & $256(88.6 \%)$ & $167(87.4 \%)$ & $89(90.8 \%)$ \\
\hline Yes & $33(11.4 \%)$ & $24(12.6 \%)$ & $9(9.2 \%)$ \\
\hline \multicolumn{4}{|l|}{ Parametrium invasion } \\
\hline No & $267(92.4 \%)$ & $176(92.1 \%)$ & $91(92.9 \%)$ \\
\hline Yes & $22(7.6 \%)$ & $15(7.9 \%)$ & $7(7.1 \%)$ \\
\hline \multicolumn{4}{|l|}{ Treatment } \\
\hline Surgery & $109(37.7 \%)$ & $71(37.2 \%)$ & $38(38.8 \%)$ \\
\hline Surgery + radiotherapy & $61(21.1 \%)$ & $44(23.0 \%)$ & $17(17.3 \%)$ \\
\hline Surgery + chemotherapy & $38(13.1 \%)$ & $24(12.6 \%)$ & $14(14.3 \%)$ \\
\hline Surgery + radiotherapy/chemotherapy & $81(28.0 \%)$ & $52(27.2 \%)$ & $29(29.6 \%)$ \\
\hline
\end{tabular}

\section{Development and validation of the histopathological nomogram}

A multiple-feature-based histological signature was built to prognose survival in the training group. After applying the LASSO logistic algorithm, five of the 22 clinical and histopathological features were finally used to develop our model (Fig. 1A and 1B). The following histopathological features had a non-zero coefficient: histological type, DOI, stromal invasion, LVI, and LNM. Histological images of the above five features are presented in Supplementary Fig. 1. Our model was created using the following formula: risk 
score $=$ histological type $\cdot-0.066+\mathrm{DOI} \cdot 0.002+$ stromal invasion $\cdot 0.218+\mathrm{LVI} \cdot 0.123+\mathrm{LNM} \cdot 0.534$. The contribution of each selected variable to signature construction is shown in Fig. 1C.

These factors were used to develop nomogram models in the training and validation groups. The histological nomograms, FIGO stage, treatment, and OS are presented in Fig. 2A and 2B. We noticed a decent calibration curve, which confirmed good agreement between prediction and observation for 1-, 3-, and 5-year OS in the training and validation cohorts (Fig. $2 \mathrm{C}-2 \mathrm{H})$.

In the training cohort, the AUCs of our 3- and 5-year models were 0.882 and 0.891 , respectively (Fig. 3A and $3 C$ ). The nomogram subsequently created was confirmed in the validation group. The AUCs of our models were 0.955 and 0.801 for 3- and 5-year OS, respectively, in the validation group (Fig. 3B and 3D).

\section{Comparing predictive accuracy between our model and the FIGO staging system}

In the training group, our model showed better discrimination ability (C-index: $0.832 ; 95 \% \mathrm{Cl}=0.751-$ 0.913 ) than both the FIGO system (C-index: $0.648 ; 95 \%$ confidence interval $[\mathrm{Cl}]=0.542-0.753$ ) and treatment (C-index: $0.687 ; 95 \% \mathrm{Cl}=0.605-0.769 ; \mathrm{p}=0.001$ for both comparisons; Table 2). In the validation group, our model showed better discrimination ability (C-index: $0.822 ; 95 \% \mathrm{Cl}=0.691-0.952 ; \mathrm{p}$ $=0.033$ and $p=0.071$ ) than the FIGO staging system (C-index: $0.599 ; 95 \% \mathrm{Cl}=0.437-0.761$ ) and treatment (C-index: $0.693 ; 95 \% \mathrm{Cl}=0.513-0.872$ ). Decision curve analysis showed that our model had higher overall net benefit (Fig. 3E and 3F). 
Table 2

The C-index of our model, Figo stage, Treatment for prediction of OS in training and validation cohort.
Factors
C-index
$95 \mathrm{Cl} \%$
$P$

For training cohort

\begin{tabular}{lll} 
Our model & 0.832 & $0.751-0.913$ \\
\hline Figo stage & 0.648 & $0.542-0.753$ \\
\hline Treatment & 0.687 & $0.605-0.769$
\end{tabular}

Our model vs Figo stage

0.001

Our model vs Treatment

0.001

For validation cohort

\begin{tabular}{lll} 
Our model & 0.822 & $0.691-0.952$ \\
\hline Figo stage & 0.599 & $0.437-0.761$ \\
\hline Treatment & 0.693 & $0.513-0.872$
\end{tabular}

Our model vs Figo stage

0.033

Our model vs Treatment

0.071

Our model includes histological type, lymph vascular invasion, depth of invasion, invasion level of uterine cervix and lymph nodes invasion;

C-index = concordance index; $P$ values are calculated based on normal approximation using function rcorrp.cens in Hmisc package.

\section{Risk stratification of OS}

At a cutoff risk-score of -1.62 (Supplementary Fig. 3), patients were categorized into high-risk (>-1.62) and low-risk groups $(\leq-1.62)$. The OS rate in the two groups is listed in Table 3 . In the training cohort, the 1-, 3-, and 5-year OS rates were $93.2 \%, 79.5 \%, 65.9 \%$, respectively, in the high-risk group, and $99.3 \%, 96.6 \%$, and $95.9 \%$, respectively in the low-risk group (Table 3). In the validation cohort, the 1-, 3-, and 5-year OS rates were $94.4 \%, 66.7 \%, 66.7 \%$, respectively, in the high-risk group, and $97.5 \%, 97.5 \%, 95.0 \%$, respectively, in the low-risk group (Table 3). Likewise, significant differences were observed for OS in patients with stage I, II, and whole ECA in the training and validation cohorts. Patients with lower risk scores generally had a better OS (Fig. 4). Each risk subgroup represented a distinct prognosis, and this system accurately separated OS in the two subgroups. Furthermore, our clustering approach revealed C1 and C2 patient groups in both cohorts (Fig. 5A and 5B). In the training and validation cohorts, the correlation coefficient between our model and FIGO stage was similar to that between our model and treatment (Fig. $5 \mathrm{C}$ and 5D). There were significantly positive correlations between our model, FIGO stage, and treatment in both cohorts (Table 4). 


\begin{tabular}{|c|c|c|c|c|c|c|}
\hline \multirow[b]{2}{*}{ Parameter } & \multicolumn{3}{|c|}{ Training cohort $(n=191)$} & \multicolumn{3}{|c|}{ Validation cohort $(n=98)$} \\
\hline & $\begin{array}{l}\text { High-risk } \\
\text { group }\end{array}$ & $\begin{array}{l}\text { Low-risk } \\
\text { group }\end{array}$ & Total & $\begin{array}{l}\text { High-risk } \\
\text { group }\end{array}$ & $\begin{array}{l}\text { Low-risk } \\
\text { group }\end{array}$ & Total \\
\hline $\begin{array}{l}\text { No. of } \\
\text { patients }\end{array}$ & 44 & 147 & 191 & 18 & 80 & 98 \\
\hline $\begin{array}{l}\text { Median } \\
(\mathrm{m})^{\star}\end{array}$ & $\begin{array}{l}36.1(12.0- \\
56.2)\end{array}$ & $\begin{array}{l}66.9(52.5- \\
84.5)\end{array}$ & $\begin{array}{l}59.4(39.1- \\
79.7)\end{array}$ & $\begin{array}{l}26.4(16.1- \\
67.1)\end{array}$ & $\begin{array}{l}73.2(56.4- \\
88.0)\end{array}$ & $\begin{array}{l}67.4(47.7- \\
85.6)\end{array}$ \\
\hline $\begin{array}{l}1-Y e a r \text { OS } \\
(\%)\end{array}$ & $41(93.2 \%)$ & $146(99.3 \%)$ & $187(97.9 \%)$ & $17(94.4 \%)$ & $78(97.5 \%)$ & $95(96.9 \%)$ \\
\hline $\begin{array}{l}\text { 3-Year OS } \\
(\%)\end{array}$ & $35(79.5 \%)$ & $142(96.6 \%)$ & $177(92.7 \%)$ & $12(66.7 \%)$ & 78(97.5\%) & $90(91.8 \%)$ \\
\hline $\begin{array}{l}5 \text {-Year OS } \\
(\%)\end{array}$ & $29(65.9 \%)$ & $141(95.9 \%)$ & $170(89.0 \%)$ & $12(66.7 \%)$ & $76(95.0 \%)$ & $88(89.8 \%)$ \\
\hline
\end{tabular}

*Data in parentheses are interquartile ranges.

\section{Discussion}

In the present study, nomograms merging pathological parameters were built to predict the 1-, 3-, and 5year OS rates of patients with ECA. Both identification and calibration were confirmed, and the nomograms will have a wide range of applications. According to the ROC curve and detrended correspondence analysis, the prognostic nomogram exhibited greater accuracy in patients with ECA than the current FIGO staging system. Furthermore, it could classify patients with ECA into low- and high-risk subpopulations, implying that it could routinely be applied to prognose ECA.

Previous research has demonstrated that histological type, DOI, stromal invasion, LVI, and LNM are highly prognostic factors, and that they currently influence patient management[17-19]. Comparing HPVA and NHPVA reveals essential differences in tumor behavior and patient survival, with significantly worse clinical outcomes in patients with NHPVA[20]. Tumors with a DOI of less than $3 \mathrm{~mm}$ (FIGO stage IA1) have lower rates of lymph-node metastases, parametrial spread, and recurrence than larger tumors (stage IA2, IB1, and IB2). Measurement of DOI is restricted[21]. Thus, stromal invasion status can complement, but should not replace, the DOI metric. Depending on variables such LVI, prognosis regarding fertility may be approved[22, 23].

Our nomogram scoring systems seemed to have outstanding capacities for prognosing ECA. Previous studies attempted to predict outcome in cervical cancer. For example, one study analyzed a four-factor model (histology, tumor size, deep stromal invasion, and LVI). The authors found that the presence of any two factors may predict recurrence in patients with cervical cancer[24]. Previous studies showed that DOI, LVI, LNM, and invasion patterns were strong independent predictors of disease-specific survival in 
ECA[19, 25-27]. By incorporating a log of odds between the number of positive lymph nodes and the number of negative lymph nodes, the nomogram by Wang may be superior to the FIGO staging system in predicting OS in cervical cancer[28]. The present study enlarged the analysis of individual H\&E morphological characteristics into a nomogram model for estimating survival, proving the histological signature's incremental signature for individualized OS estimation. Our model consisted of five histological characteristics and provided a non-invasive, quick, low-cost, and reproducible method for collecting phenotypic information. As such, it may inform attempts to improve personalized medicine.

However, the present study had several deficiencies. Firstly, there may have been a selection bias because patients with ECA in situ were not enrolled in the nomograms. Secondly, our study only assessed OS prognosis in patients with ECA. Thirdly, the sample size was rather small. Therefore, another study must be conducted to verify the nomogram.

\section{Conclusions}

In summary, we generated new nomograms to prognose the OS rate in patients with ECA. Our simple and explicit nomograms have good clinical application value, and they show good discrimination and calibration ability. They may be a useful tool for assessing prognosis and managing treatment in patients with ECA.

\section{Declarations}

\section{Ethics approval and consent to participate}

This study was approved by the Clinical Research Ethics Committee of the Sun Yat-sen University Cancer Center, and all patients provided written informed consent at the first visit to our center.

\section{Consent for publication}

Not applicable.

\section{Availability of data and materials}

The authenticity of this article has been validated by uploading the key raw data onto the Research Data Deposit public platform (www.researchdata.org.cn) with the approval RDD number RDDB2020000652.

\section{Competing interests}

The authors declare that they have no competing interests.

\section{Funding}

This work was supported by the National Natural Science Foundation of China (No. 8207100308). 
Authors' contributions

Conception and design: Rong-Zhen Luo. Performing experiments: Li-Li Liu and Xia Yang. Drafting of the article: Li-Li Liu and Shu-Lin Chen. Acquisition and interpretation of data, review, editing and approval of the manuscript: all authors.

\section{Acknowledgements}

We thank Sun Yat-sen University Cancer Center for providing support on research conditions in this study.

\section{References}

1. Smith HO, Tiffany MF, Qualls CR, Key CR: The rising incidence of adenocarcinoma relative to squamous cell carcinoma of the uterine cervix in the United States-a 24-year population-based study. Gynecol Oncol 2000, 78(2):97-105.

2. Kenny SL, McBride HA, Jamison J, McCluggage WG: Mesonephric adenocarcinomas of the uterine cervix and corpus: HPV-negative neoplasms that are commonly PAX8, CA125, and HMGA2 positive and that may be immunoreactive with TTF1 and hepatocyte nuclear factor 1-beta. Am J Surg Pathol 2012, 36(6):799-807.

3. Ito M, Minamiguchi S, Mikami Y, Ueda Y, Sekiyama K, Yamamoto T, Takakura K: Peutz-Jeghers syndrome-associated atypical mucinous proliferation of the uterine cervix: a case of minimal deviation adenocarcinoma ('adenoma malignum') in situ. Pathol Res Pract 2012, 208(10):623-627.

4. Kocken M, Baalbergen A, Snijders PJ, Bulten J, Quint WG, Smedts F, Meijer CJ, Helmerhorst TJ: Highrisk human papillomavirus seems not involved in DES-related and of limited importance in nonDES related clear-cell carcinoma of the cervix. Gynecol Oncol 2011, 122(2):297-302.

5. Karamurzin YS, Kiyokawa T, Parkash V, Jotwani AR, Patel P, Pike MC, Soslow RA, Park KJ: Gastrictype Endocervical Adenocarcinoma: An Aggressive Tumor With Unusual Metastatic Patterns and Poor Prognosis. Am J Surg Pathol 2015, 39(11):1449-1457.

6. Kojima A, Mikami Y, Sudo T, Yamaguchi S, Kusanagi Y, Ito M, Nishimura R: Gastric morphology and immunophenotype predict poor outcome in mucinous adenocarcinoma of the uterine cervix. $A m \mathrm{~J}$ Surg Pathol 2007, 31(5):664-672.

7. RJ K, ML C, CS H, RH Y: WHO Classification of Tumors of Female Reproductive Organs, 4th ed. Lyon: IARC, WHO Press 2014.

8. Ronnett BM: Endocervical adenocarcinoma: selected diagnostic challenges. Mod Patho/ 2016, 29 Suppl 1:S12-28.

9. Baalbergen A, Ewing-Graham PC, Hop WC, Struijk P, Helmerhorst TJ: Prognostic factors in adenocarcinoma of the uterine cervix. Gynecol Oncol 2004, 92(1):262-267.

10. Stolnicu S, Barsan I, Hoang L, Patel P, Terinte C, Pesci A, Aviel-Ronen S, Kiyokawa T, Alvarado-Cabrero I, Pike MC et al: International Endocervical Adenocarcinoma Criteria and Classification (IECC): A New 
Pathogenetic Classification for Invasive Adenocarcinomas of the Endocervix. Am J Surg Pathol 2018, 42(2):214-226.

11. Diaz De Vivar A, Roma AA, Park KJ, Alvarado-Cabrero I, Rasty G, Chanona-Vilchis JG, Mikami Y, Hong $\mathrm{SR}$, Arville B, Teramoto $\mathrm{N}$ et al: Invasive endocervical adenocarcinoma: proposal for a new patternbased classification system with significant clinical implications: a multi-institutional study. Int $J$ Gynecol Pathol 2013, 32(6):592-601.

12. Roma AA: Patterns of Invasion of Cervical Adenocarcinoma as Predicators of Outcome. Adv Anat Pathol 2015, 22(6):345-354.

13. Roma AA, Mistretta TA, Diaz De Vivar A, Park KJ, Alvarado-Cabrero I, Rasty G, Chanona-Vilchis JG, Mikami Y, Hong SR, Teramoto $\mathrm{N}$ et al: New pattern-based personalized risk stratification system for endocervical adenocarcinoma with important clinical implications and surgical outcome. Gynecol Oncol 2016, 141(1):36-42.

14. Roma $A A$, Fadare 0 : The pattern is the issue: recent advances in adenocarcinoma of the uterine cervix. Virchows Arch 2018, 472(6):897-905.

15. Rivera-Colon G, Chen H, Niu S, Lucas E, Holloway S, Carrick K, Gwin K, Lea J, Zheng W: Cervical Adenocarcinoma: Histopathologic Features From Biopsies to Predict Tumor Behavior. Am J Surg Pathol 2020, 44(2):247-254.

16. Ito K, Seguchi K, Shimazaki H, Takahashi E, Tasaki S, Kuroda K, Sato A, Asakuma J, Horiguchi A, Asano $\mathrm{T}$ : Tumor necrosis is a strong predictor for recurrence in patients with pathological T1a renal cell carcinoma. Oncol Lett 2015, 9(1):125-130.

17. Parra-Herran C, Taljaard M, Djordjevic B, Reyes MC, Schwartz L, Schoolmeester JK, Lastra RR, Quick CM, Laury A, Rasty G et al: Pattern-based classification of invasive endocervical adenocarcinoma, depth of invasion measurement and distinction from adenocarcinoma in situ: interobserver variation among gynecologic pathologists. Mod Pathol 2016, 29(8):879-892.

18. Stolnicu S, Hoang L, Chiu D, Hanko-Bauer O, Terinte C, Pesci A, Aviel-Ronen S, Kiyokawa T, AlvaradoCabrero I, Oliva E et al: Previous study identified a four-factor model (histology, tumor size, deep stromal invasion and $\mathrm{LVI}$ ) in which the presence of any two factors may be useful for predicting recurrence in patients with cervical cancer. . Am J Surg Pathol 2019, 43(4):466-474.

19. Spaans VM, Scheunhage DA, Barzaghi B, de Kroon CD, Fleuren GJ, Bosse T, Jordanova ES: Independent validation of the prognostic significance of invasion patterns in endocervical adenocarcinoma: Pattern A predicts excellent survival. Gynecol Oncol 2018, 151(2):196-201.

20. Rodriguez-Carunchio L, Soveral I, Steenbergen RD, Torne A, Martinez S, Fuste P, Pahisa J, Marimon L, Ordi J, del Pino M: HPV-negative carcinoma of the uterine cervix: a distinct type of cervical cancer with poor prognosis. BJOG 2015, 122(1):119-127.

21. Poynor EA, Marshall D, Sonoda Y, Slomovitz BM, Barakat RR, Soslow RA: Clinicopathologic features of early adenocarcinoma of the cervix initially managed with cervical conization. Gynecol Oncol 2006, 103(3):960-965. 
22. Hacker NF: Revised FIGO staging for carcinoma of the vulva. Int J Gynaecol Obstet 2009, 105(2):105106.

23. Roma AA, Park KJ, Xie H, De Vivar AD, Alvarado-Cabrero I, Rutgers JKL, Barbuto D, Silva EG: Role of Lymphovascular Invasion in Pattern C Invasive Endocervical Adenocarcinoma. Am J Surg Pathol 2017, 41(9):1205-1211.

24. Ryu SY, Kim MH, Nam BH, Lee TS, Song ES, Park CY, Kim JW, Kim YB, Ryu HS, Park SY et al: Intermediate-risk grouping of cervical cancer patients treated with radical hysterectomy: a Korean Gynecologic Oncology Group study. Br J Cancer 2014, 110(2):278-285.

25. Byun JM, Cho HJ, Park HY, Kim YN, Lee KB, Sung MS, Jeong CH, Jeong DH: Clinical significance of the pattern-based classification in endocervical adenocarcinoma, usual and variants. Int J Clin Oncol 2019, 24(10):1264-1272.

26. Sedlis A, Bundy BN, Rotman MZ, Lentz SS, Muderspach LI, Zaino RJ: A randomized trial of pelvic radiation therapy versus no further therapy in selected patients with stage IB carcinoma of the cervix after radical hysterectomy and pelvic lymphadenectomy: A Gynecologic Oncology Group Study. Gynecol Oncol 1999, 73(2):177-183.

27. McCluggage WG: New developments in endocervical glandular lesions. Histopathology 2013, 62(1):138-160.

28. Wang C, Yang C, Wang W, Xia B, Li K, Sun F, Hou Y: A Prognostic Nomogram for Cervical Cancer after Surgery from SEER Database. J Cancer 2018, 9(21):3923-3928.

\section{Supplementary Information}

\begin{tabular}{|c|c|c|}
\hline \multicolumn{3}{|c|}{ Supplementary Table 1. The correlation between our model, Figo stage and Treatmen } \\
\hline Models & Correlation coefficients ${ }^{a}$ & $P$ value \\
\hline \multicolumn{3}{|l|}{ For training cohort } \\
\hline Our model vs. Figo stage & 0.473 & $<0.001$ \\
\hline Our model vs. Treatment & 0.512 & $<0.001$ \\
\hline \multicolumn{3}{|l|}{ For validation cohort } \\
\hline Our model vs. Figo stage & 0.311 & 0.002 \\
\hline Our model vs. Treatment & 0.575 & $<0.001$ \\
\hline
\end{tabular}

a: Pearson's correlation coefficient.

Supplementary Figure-1. Representative images for other histopathological features in paraffin embedded ECA samples. Representative images for growth pattern A, B, C (A), nuclear grade (B), tumor 
cell necrotic debris (C), tumor giant cells (D), tumoral TILs (E) and stromal TILs (F) were shown.

Supplementary Figure-2. The best cut-off values for subgroups were determined by X-tile in all ECA cases. The best cut-off values for low-risk group and high-risk group were determined by X-tile.

Supplementary Figure-3. Bioinformatic analyses indicated that the subgroups based on the $\mathbf{5}$ histologic features, FIGO stage and treatment. (A-B) Heatmaps showing the results of 3 subgroups based on the 5 predictors from our nomogram model, FIGO stage and treatment for training cohort and validation cohort. (C-D) The circus diagram showed that our model, FIGO stage and treatment were significantly correlated in training cohort and validation cohort.

\section{Figures}




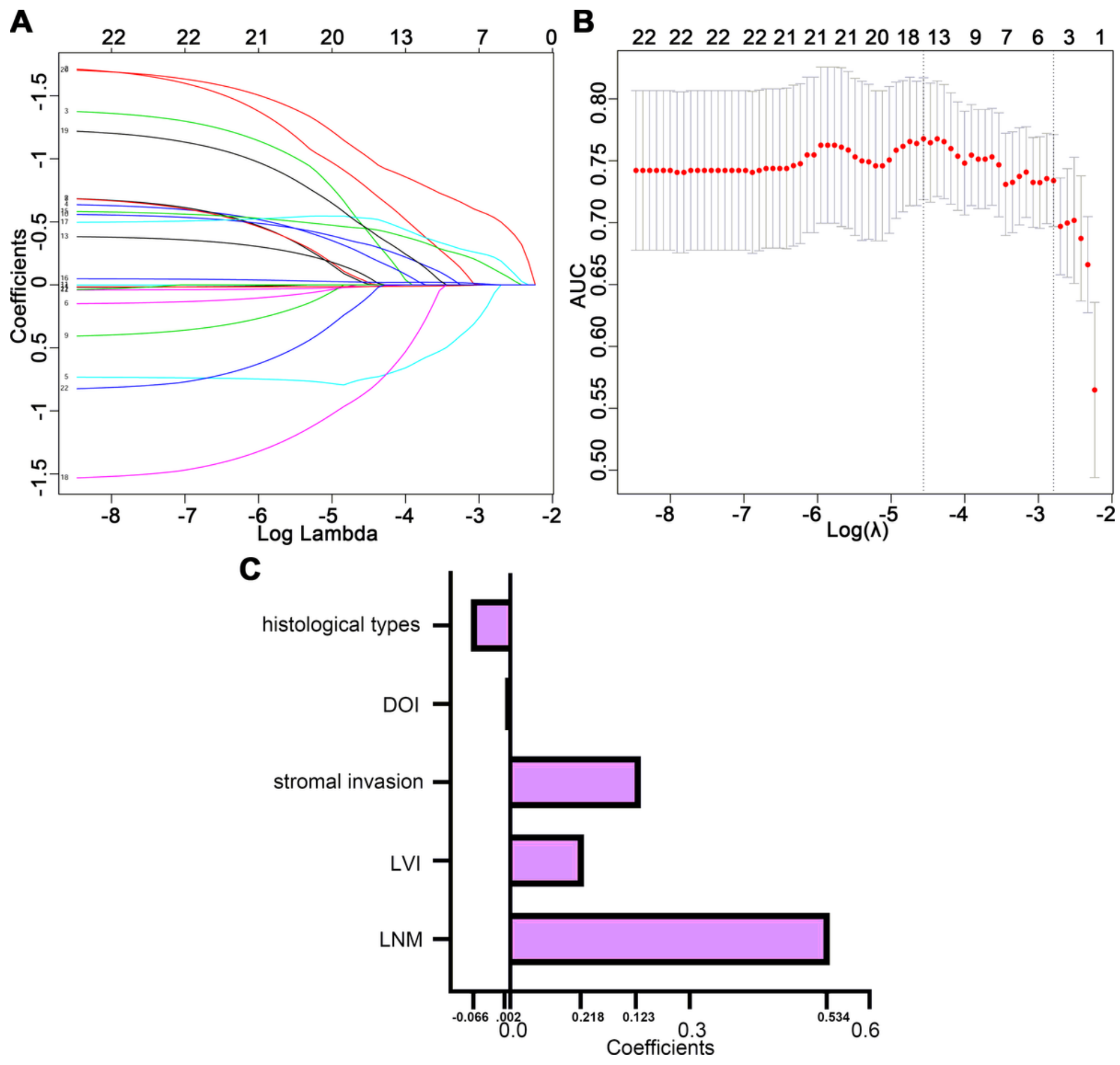

\section{Figure 1}

Texture feature selection using the least absolute shrinkage and selection operator (LASSO) binary logistic regression model. (A) LASSO coefficient profiles, displaying 22 texture features. A coefficient profile plot was produced against the log (lambda) sequence. Each colored line represents the coefficient of individual feature. (B) Tuning parameter (log lambda) selection in the LASSO model used tenfold cross-validation via minimum criteria. Vertical dotted lines were drawn at the selected $\lambda$ values. (C) Histogram shows the role of histologic features that contribute to our model. The features that contribute to our model are plotted on the $y$-axis, with their coefficients in the LASSO Cox analysis plotted on the $x$ axis. 


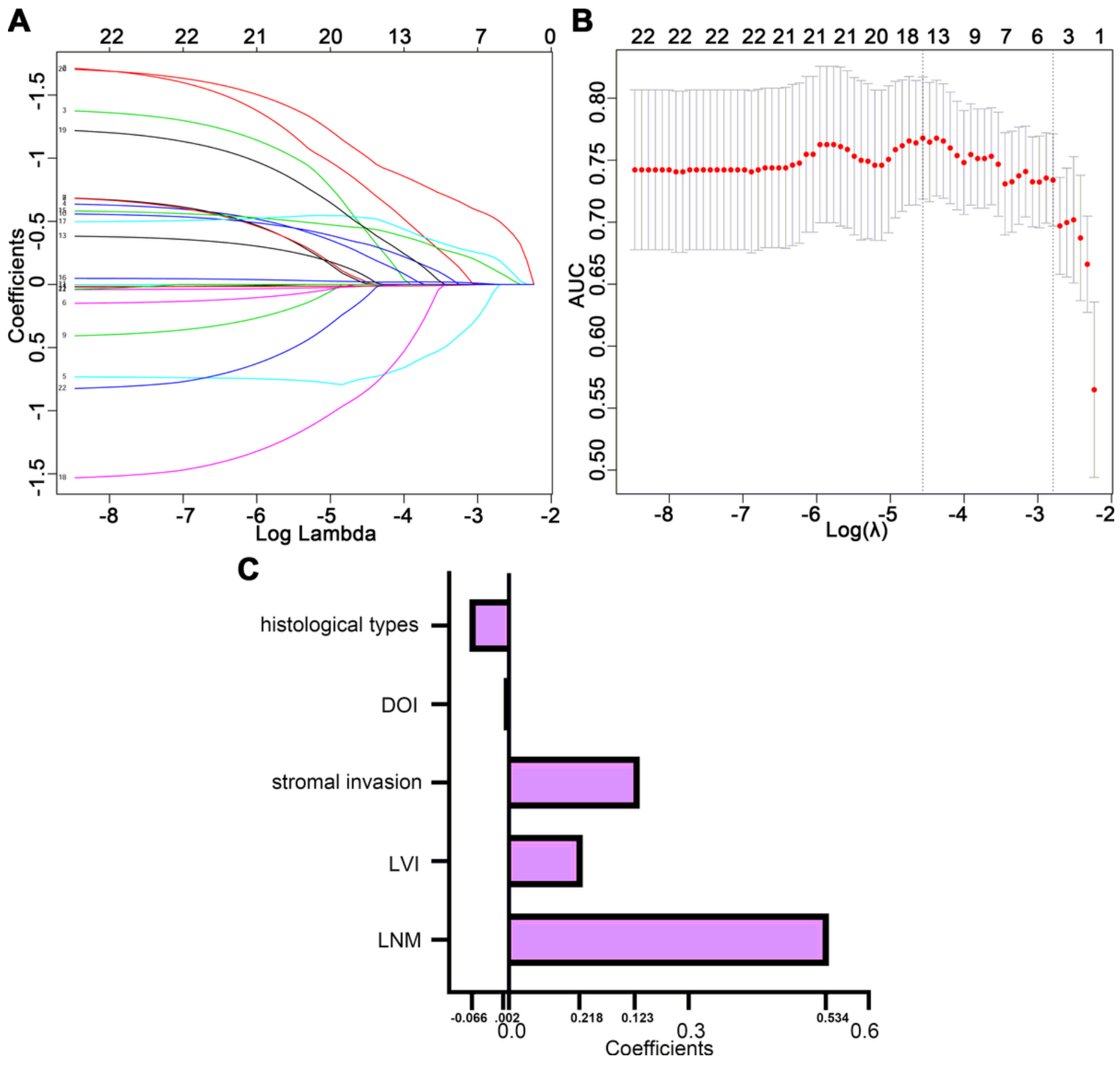

\section{Figure 1}

Texture feature selection using the least absolute shrinkage and selection operator (LASSO) binary logistic regression model. (A) LASSO coefficient profiles, displaying 22 texture features. A coefficient profile plot was produced against the log (lambda) sequence. Each colored line represents the coefficient of individual feature. (B) Tuning parameter (log lambda) selection in the LASSO model used tenfold cross-validation via minimum criteria. Vertical dotted lines were drawn at the selected $\lambda$ values. (C) Histogram shows the role of histologic features that contribute to our model. The features that contribute to our model are plotted on the $y$-axis, with their coefficients in the LASSO Cox analysis plotted on the $x$ axis. 

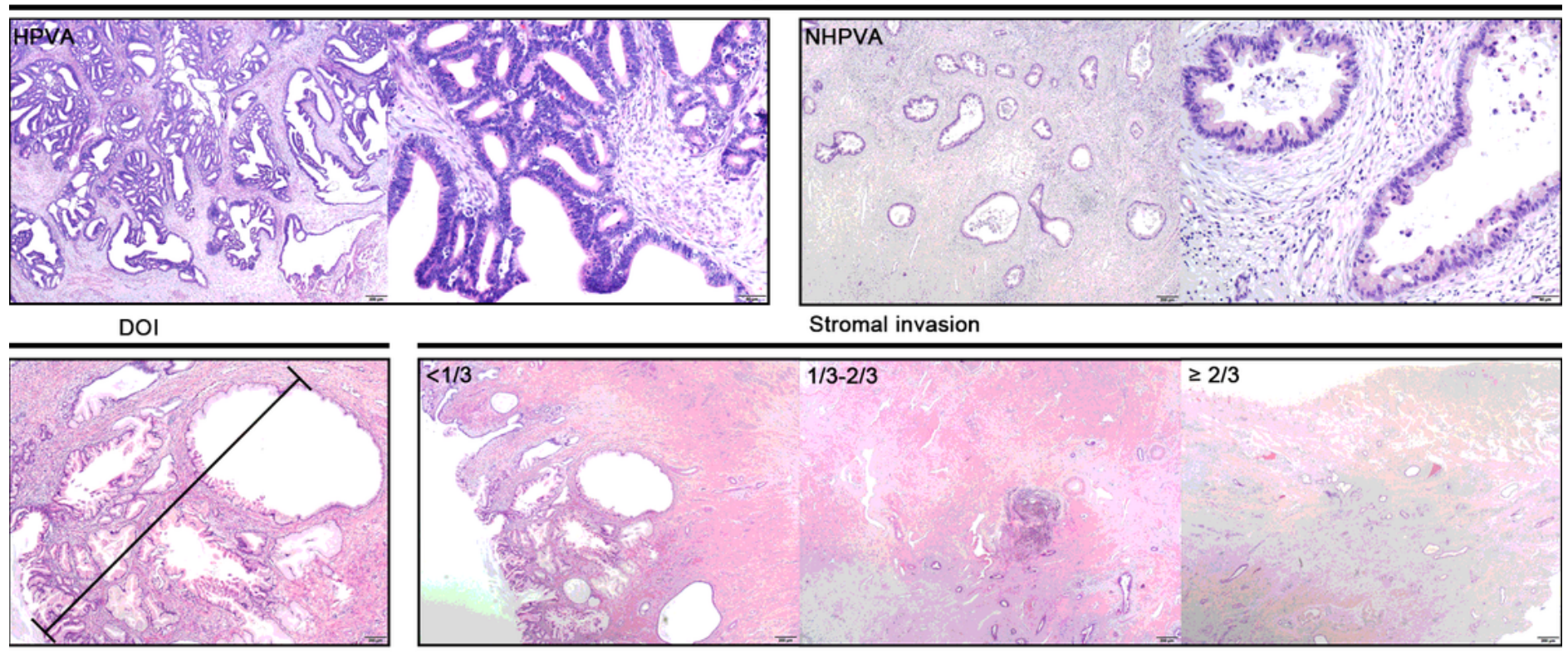

LNM
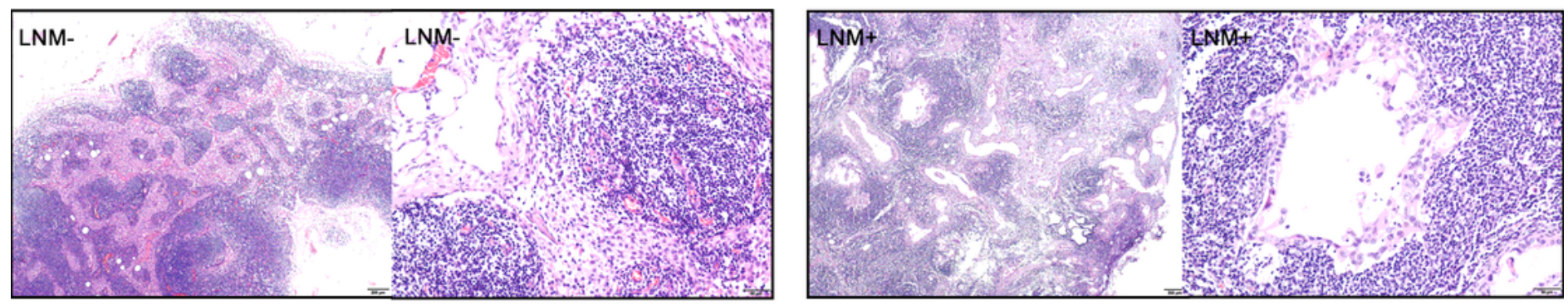

LVI
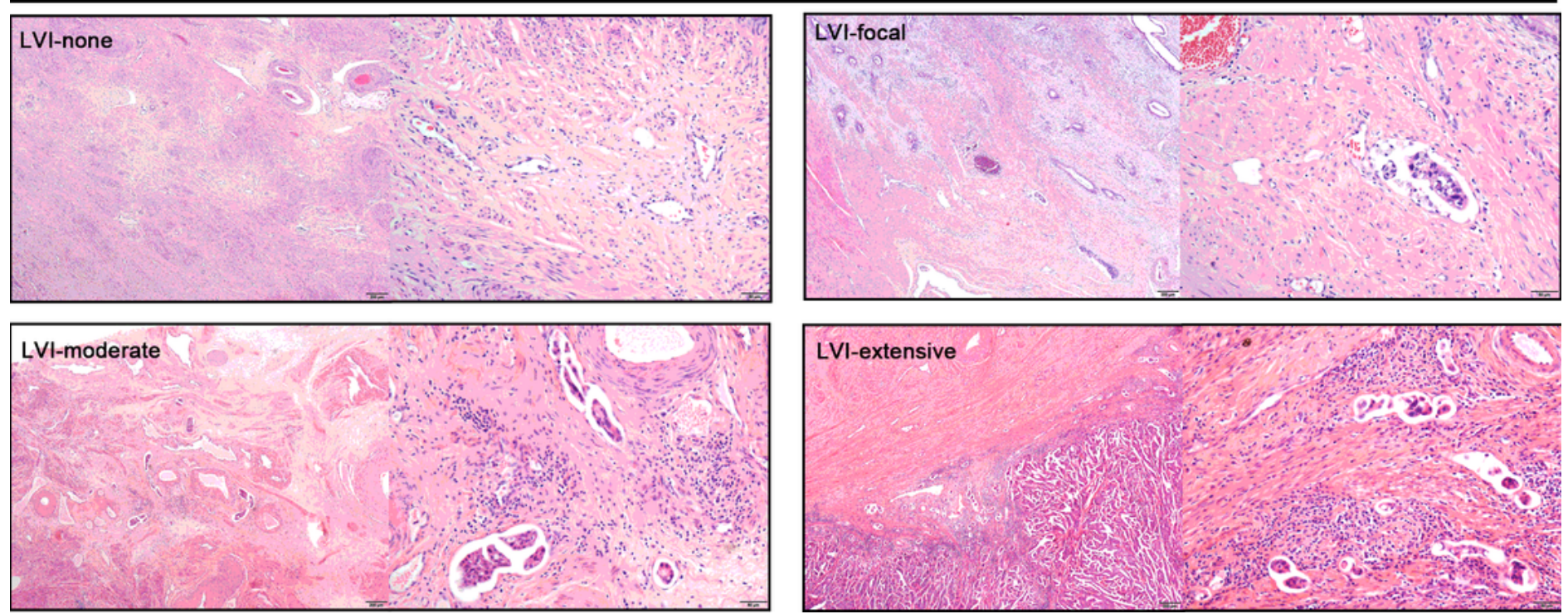

\section{Figure 2}

Representative images for 5 histopathological features in paraffin embedded ECA samples.

Representative images for histologic type (HPVA and NHPVA) (A), depth of invasion (B), stromal invasion (C), LVI(D), LNM (E) were shown. Representative images for 5 histopathological features in paraffin embedded ECA samples. Representative images for histologic type (HPVA and NHPVA) (A), depth of invasion (B), stromal invasion (C), LVI(D), LNM (E) were shown. 

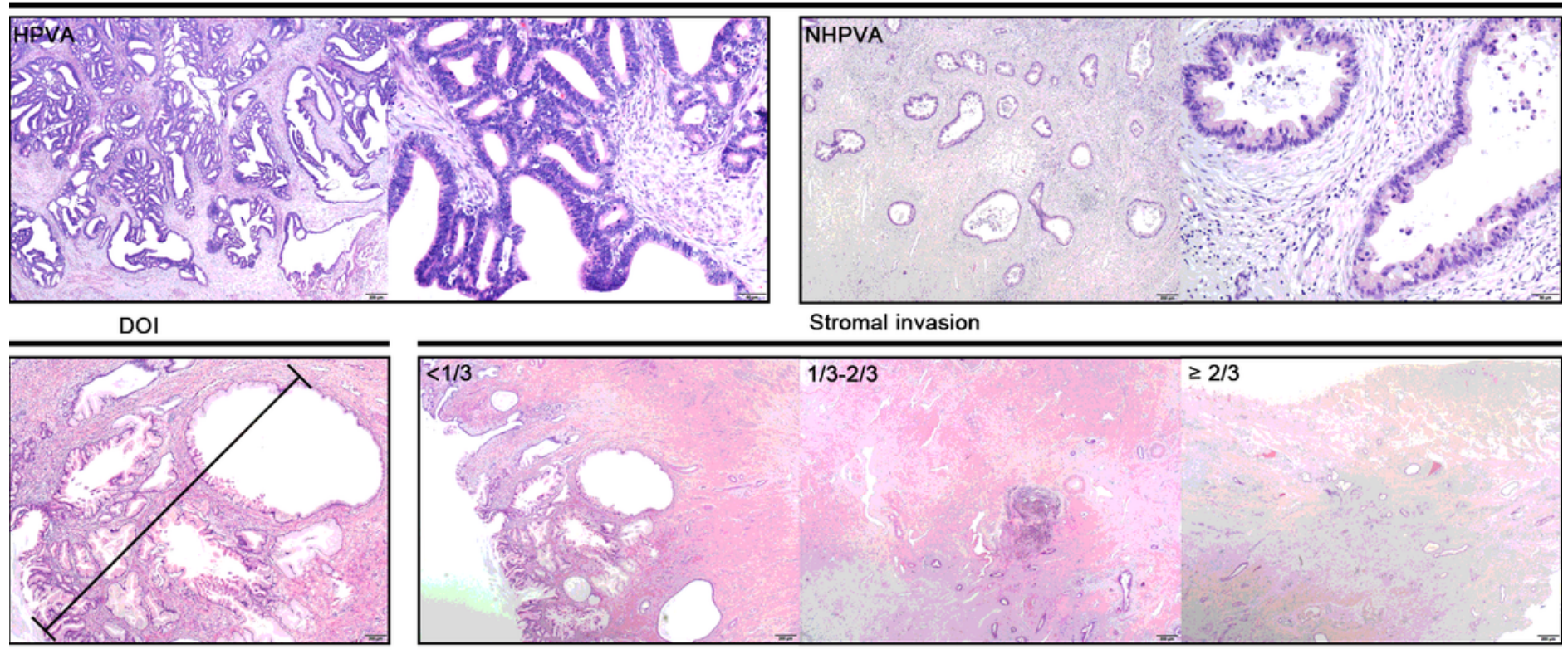

LNM
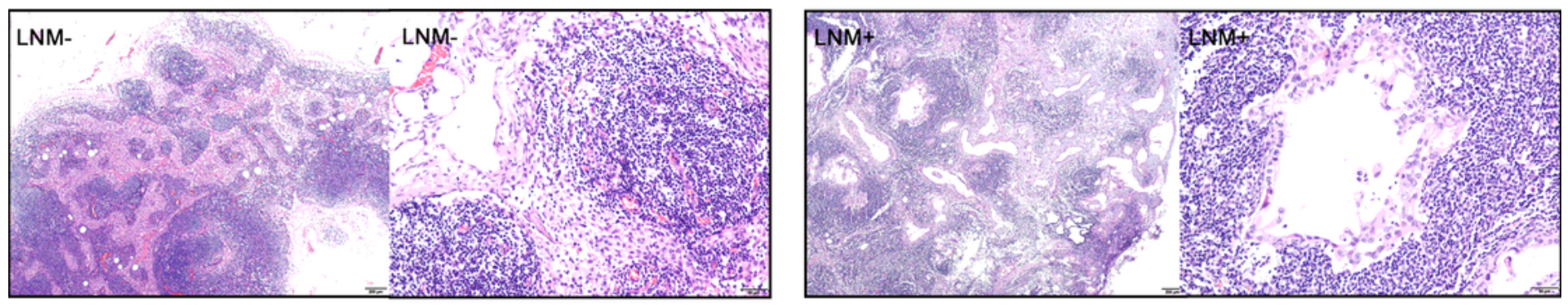

LVI
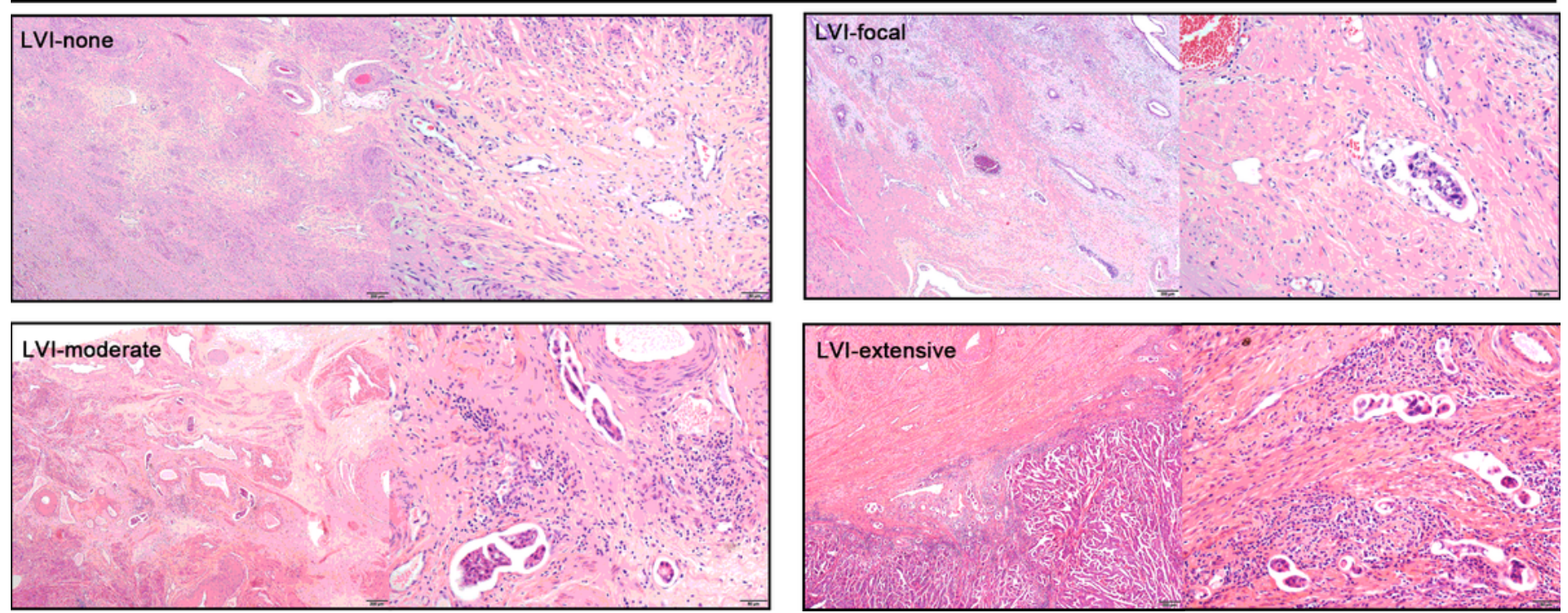

\section{Figure 2}

Representative images for 5 histopathological features in paraffin embedded ECA samples.

Representative images for histologic type (HPVA and NHPVA) (A), depth of invasion (B), stromal invasion (C), LVI(D), LNM (E) were shown. Representative images for 5 histopathological features in paraffin embedded ECA samples. Representative images for histologic type (HPVA and NHPVA) (A), depth of invasion (B), stromal invasion (C), LVI(D), LNM (E) were shown. 


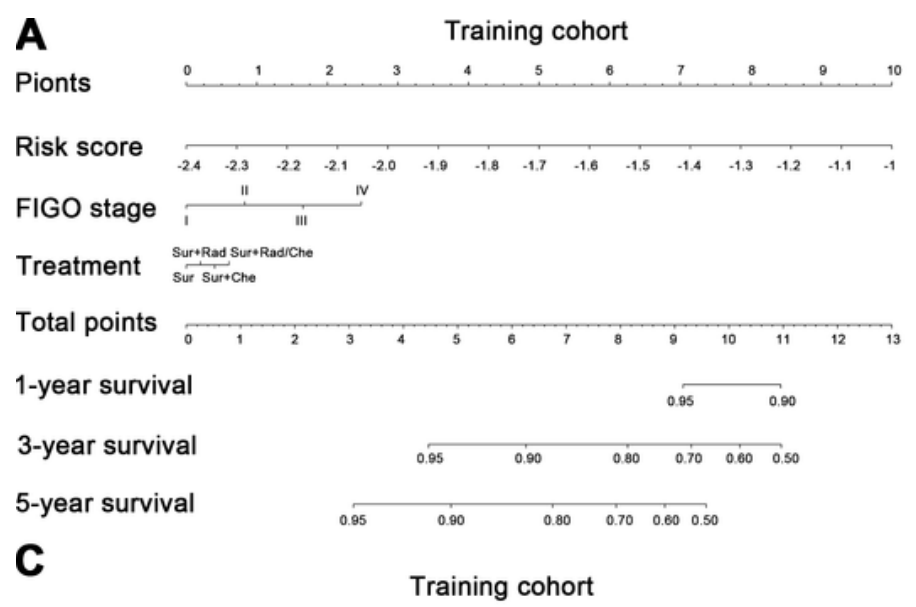

B

Pionts

Validation cohort

$\begin{array}{llllllllllllllll}\text { Risk score } & -2.4 & -2.3 & -2.2 & -2.1 & -2.0 & -1.9 & -1.8 & -1.7 & -1.6 & -1.5 & -1.4 & -1.3 & -1.2 & -1.1\end{array}$ FIGO stage , " III

Treatment $\substack{\text { Sur } \\ \text { Surr:Radche }}$,

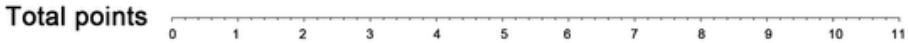

1-year survival

3-year survival

$\begin{array}{llll}0.95 \quad 0.90 & 0.80 & 0.70\end{array}$

5-year survival

D

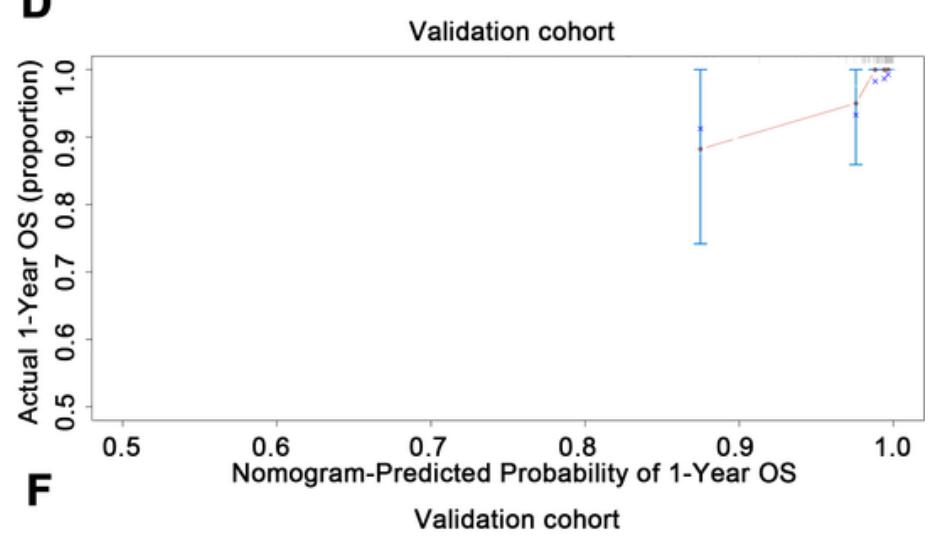

E

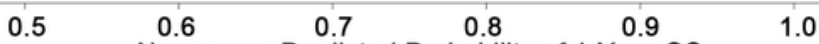

E $\quad$ Nomogram-Predicted Probability

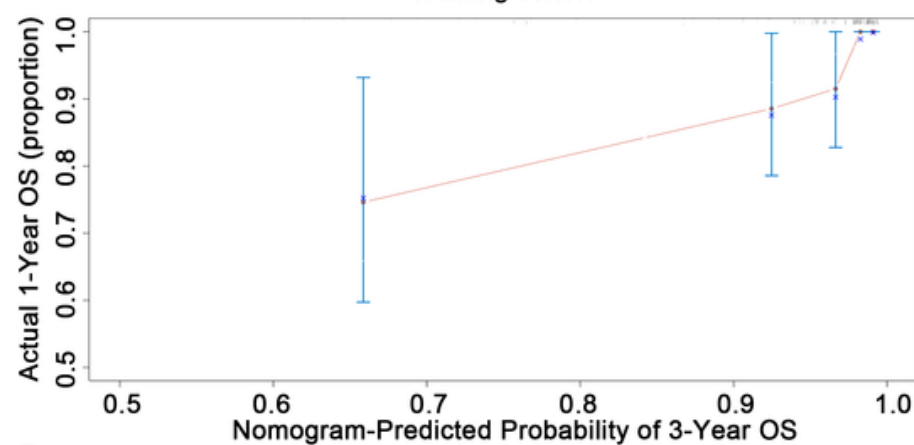

G

Training cohort
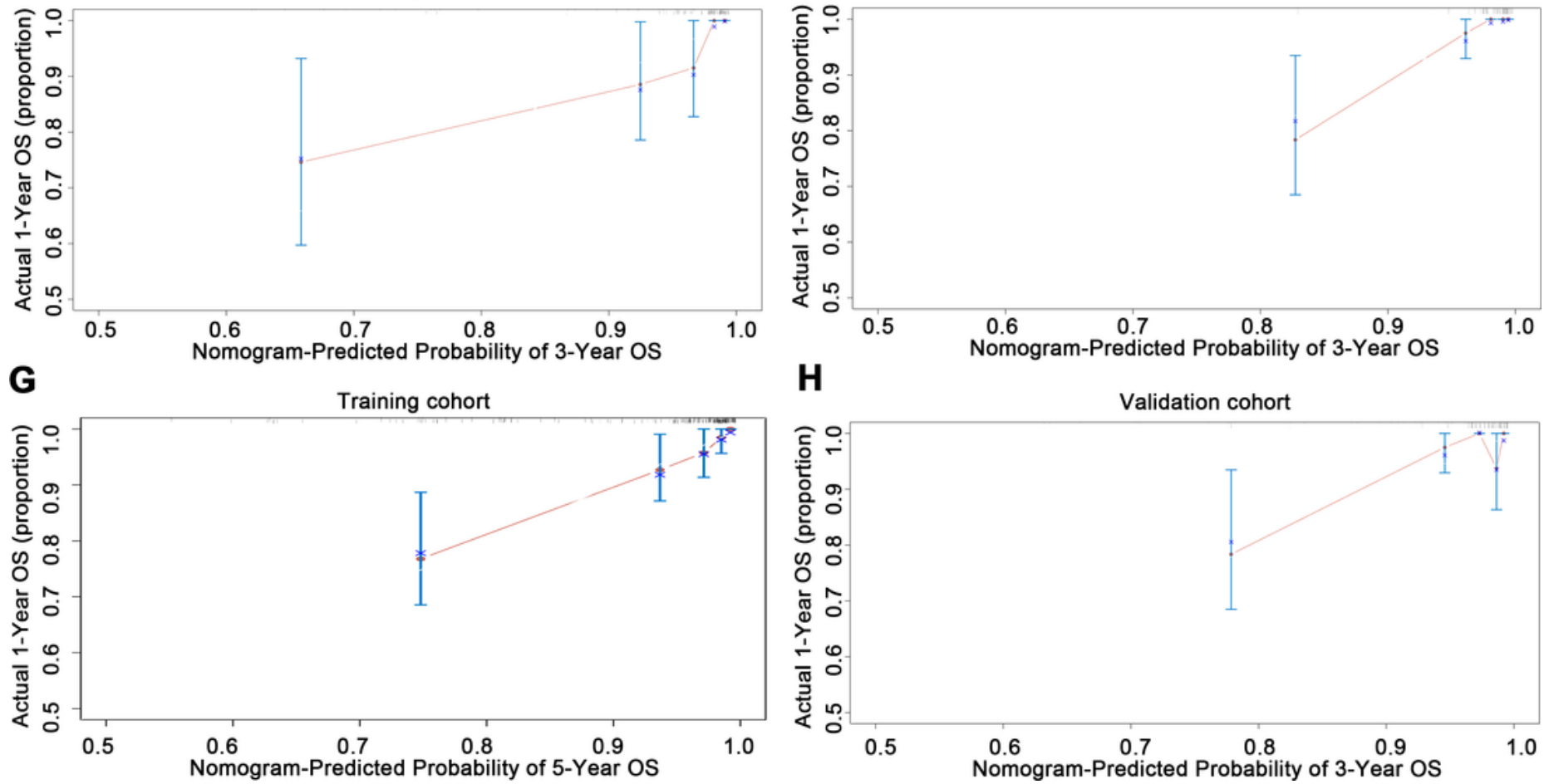

H

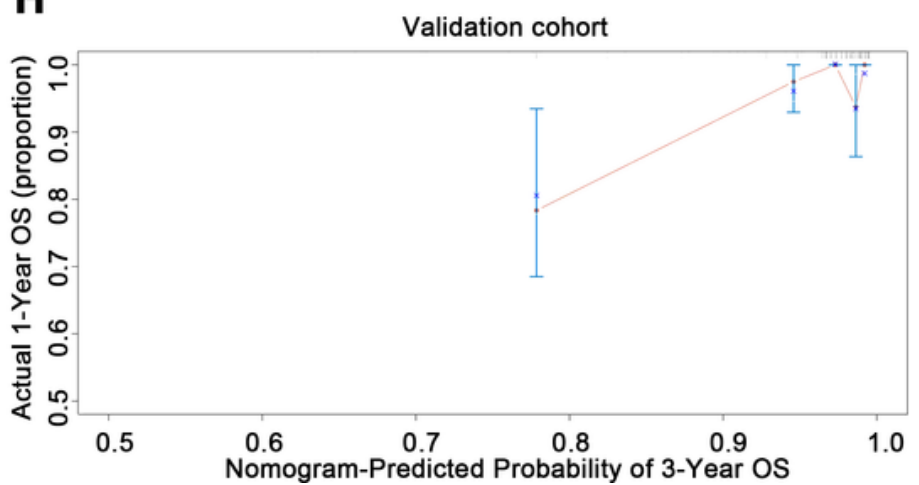

Figure 3

Use of the constructed histological nomogram to estimate OS for ECA, along with the assessment of the model calibration. (A-B) The nomogram models for training cohort and validation cohort were used summing the points identified on the points scale for each variable. The total points profected on the bottom scales indicate the probability of 1-year, 3-year and 5-year survival. (C, E, G) The calibration curves 
for predicting patients' OS at 1-year, 3-year and 5-year in the training cohort. (D, F, H) The calibration curves for predicting patients' OS at 1-year, 3-year and 5-year in the validation cohort.
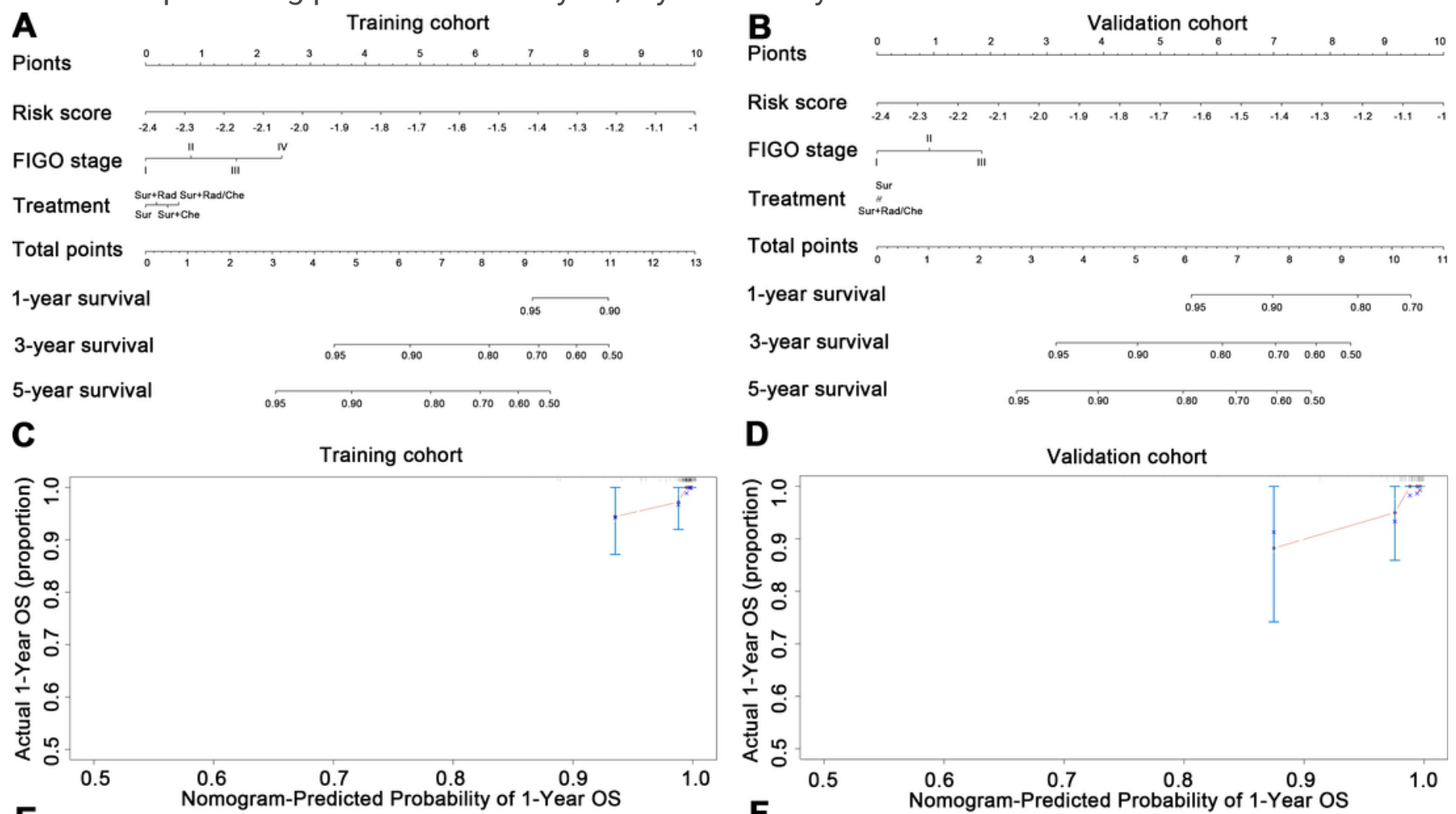

D

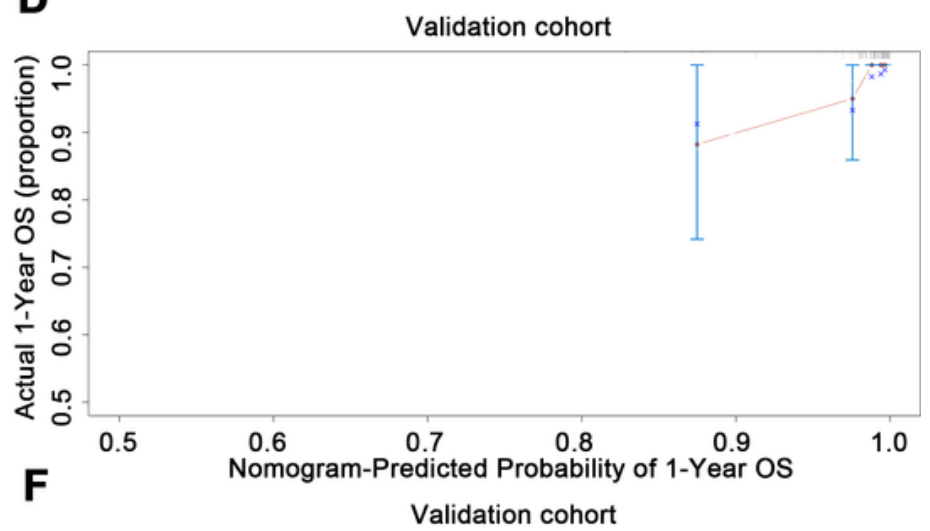

E

Training cohort

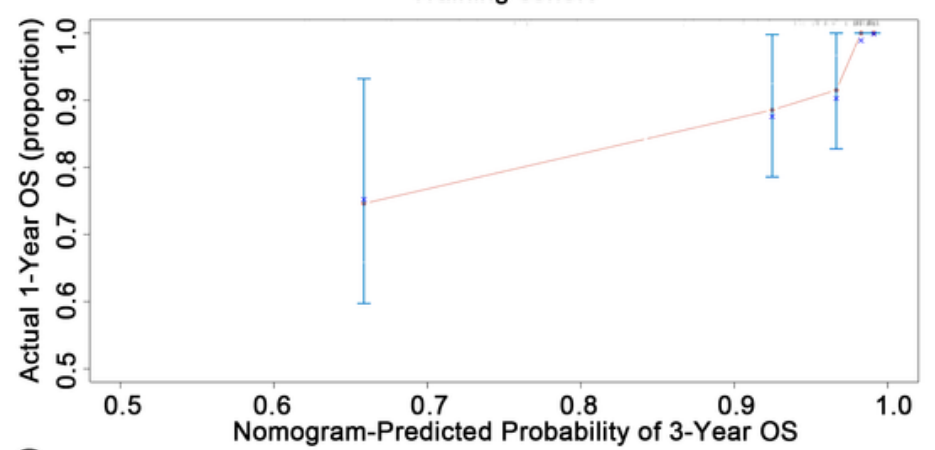

G
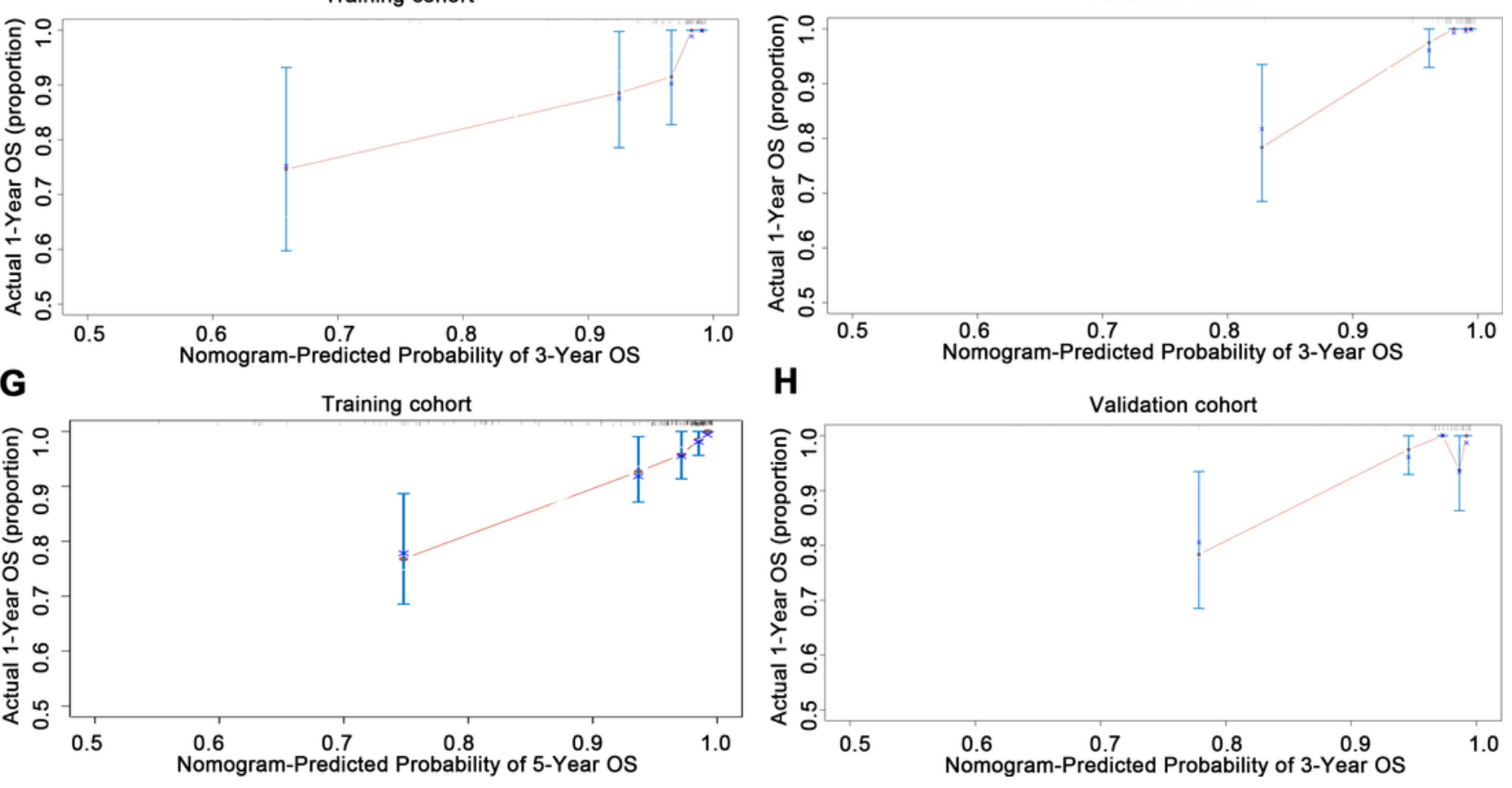

H

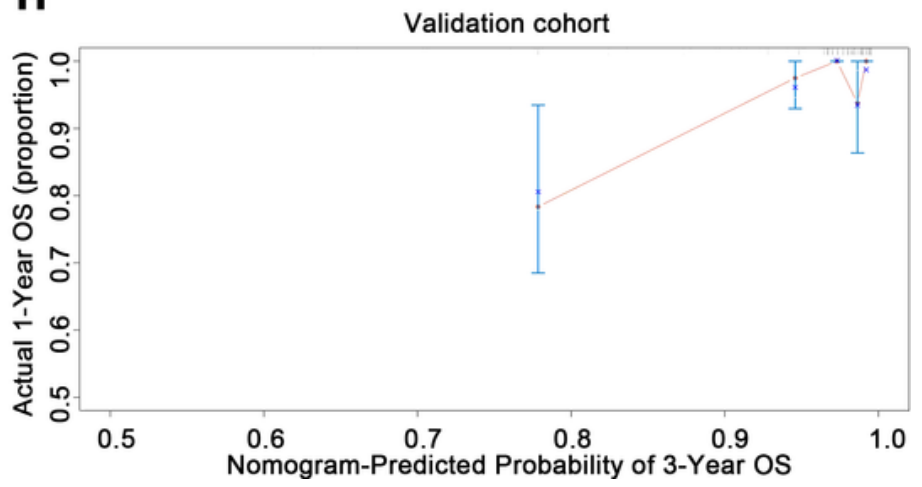

Figure 3

Use of the constructed histological nomogram to estimate OS for ECA, along with the assessment of the model calibration. (A-B) The nomogram models for training cohort and validation cohort were used summing the points identified on the points scale for each variable. The total points profected on the 
bottom scales indicate the probability of 1-year, 3-year and 5-year survival. (C, E, G) The calibration curves for predicting patients' OS at 1-year, 3-year and 5-year in the training cohort. (D, F, H) The calibration curves for predicting patients' OS at 1-year, 3-year and 5-year in the validation cohort.
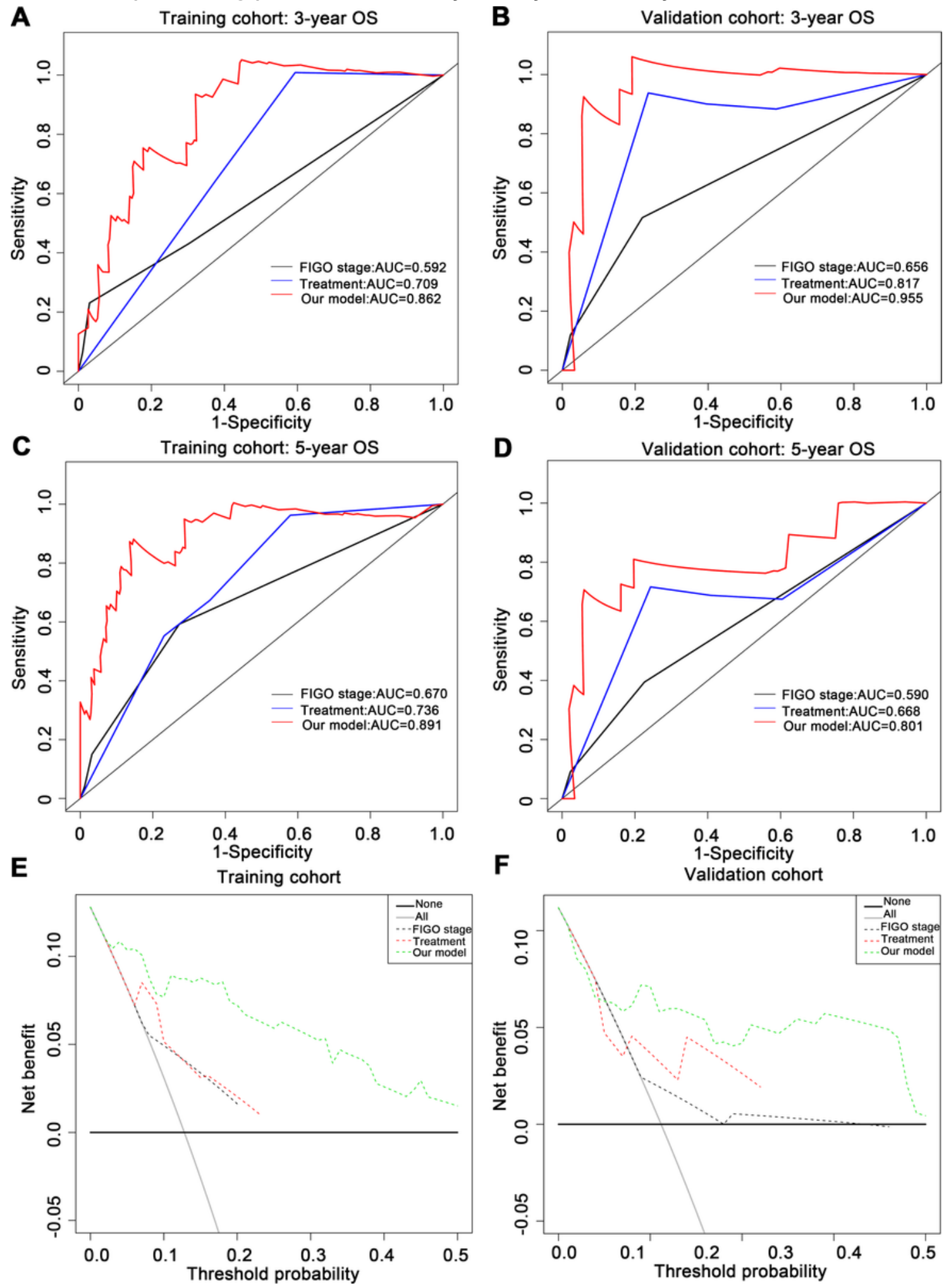

Figure 4

AUC of the histopathological score and decision curve analysis in prediction of OS. (A-B) 3-year AUC of the histopathological score in the training cohort and validation cohort. (C-D) 5-year AUC of the 
histopathological score in the training cohort and validation cohort. (E-F) Decision curve analysis for 1year, 3-year and 5-year survival predictions.
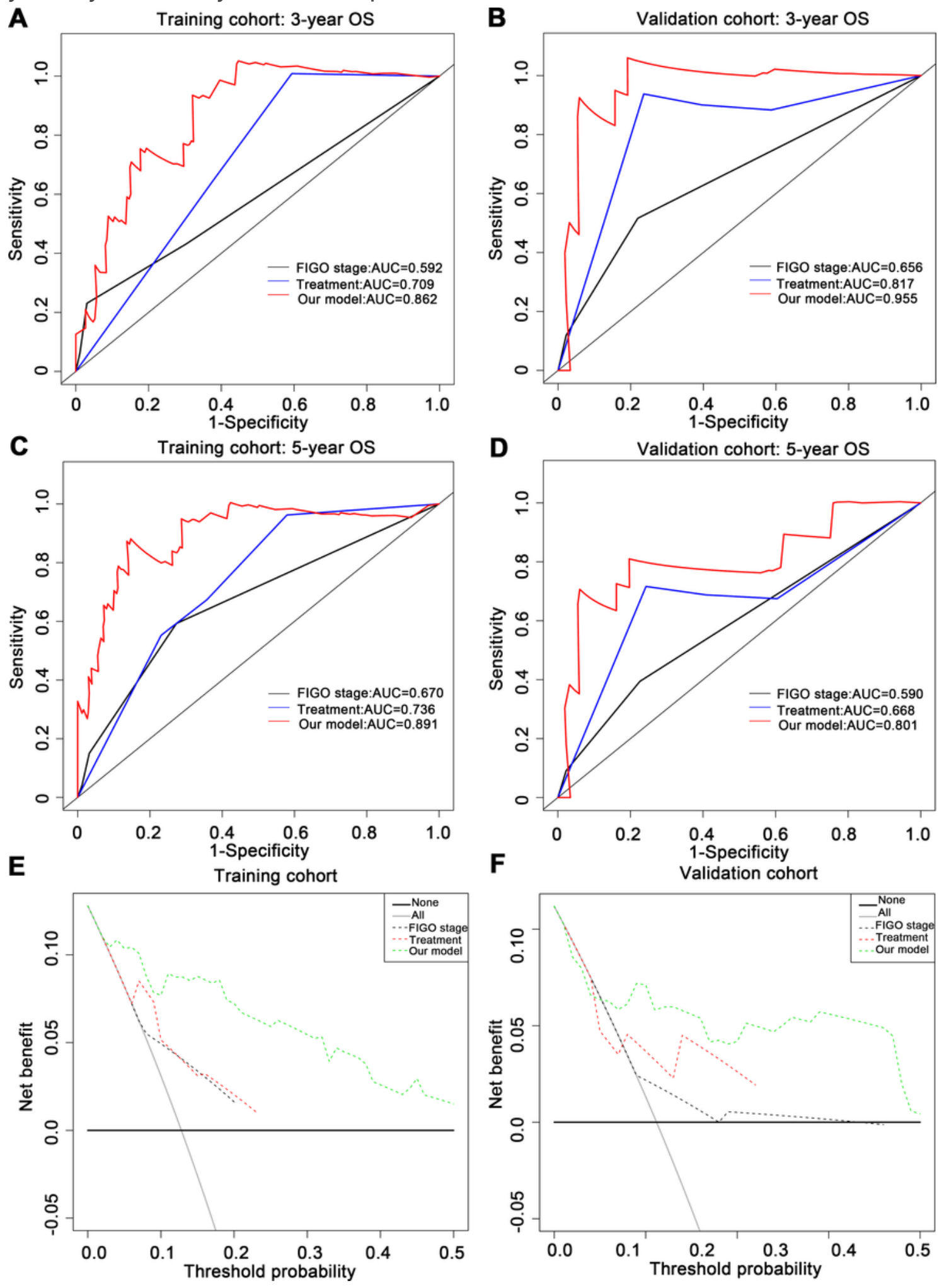

Figure 4

AUC of the histopathological score and decision curve analysis in prediction of OS. (A-B) 3-year AUC of the histopathological score in the training cohort and validation cohort. (C-D) 5-year AUC of the 
histopathological score in the training cohort and validation cohort. (E-F) Decision curve analysis for 1year, 3-year and 5-year survival predictions.

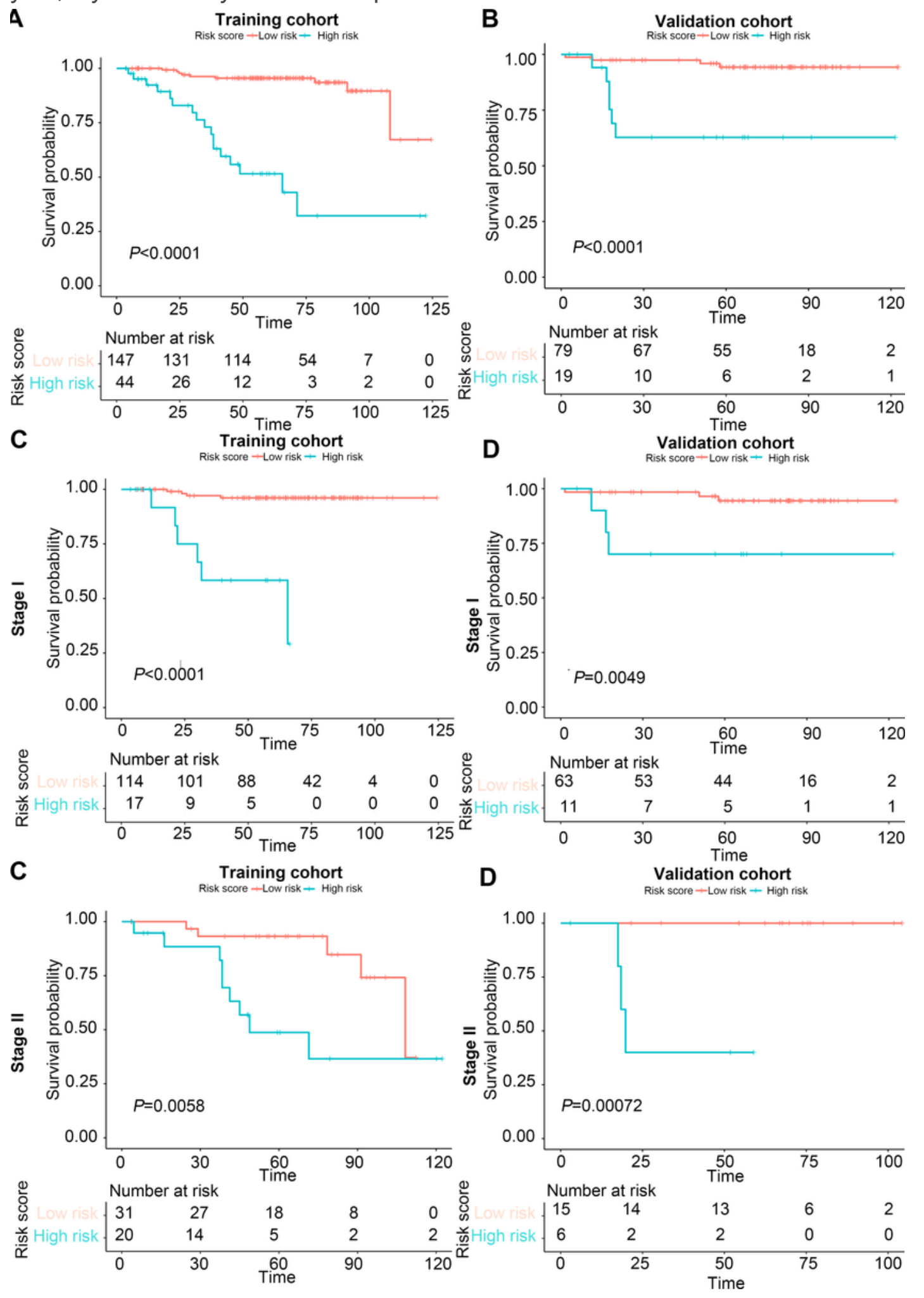

Figure 5

Graphs showing the results of Kaplan-Meier curves for all two groups based on the predictors from the nomogram model. (A-C) Graphs showing the results of Kaplan-Meier curves for all two groups based on 
the predictors from the nomogram model in all patients, stage I and stage II of training cohort $(A, C, E)$ and validation cohort $(B, D, F)$.

A
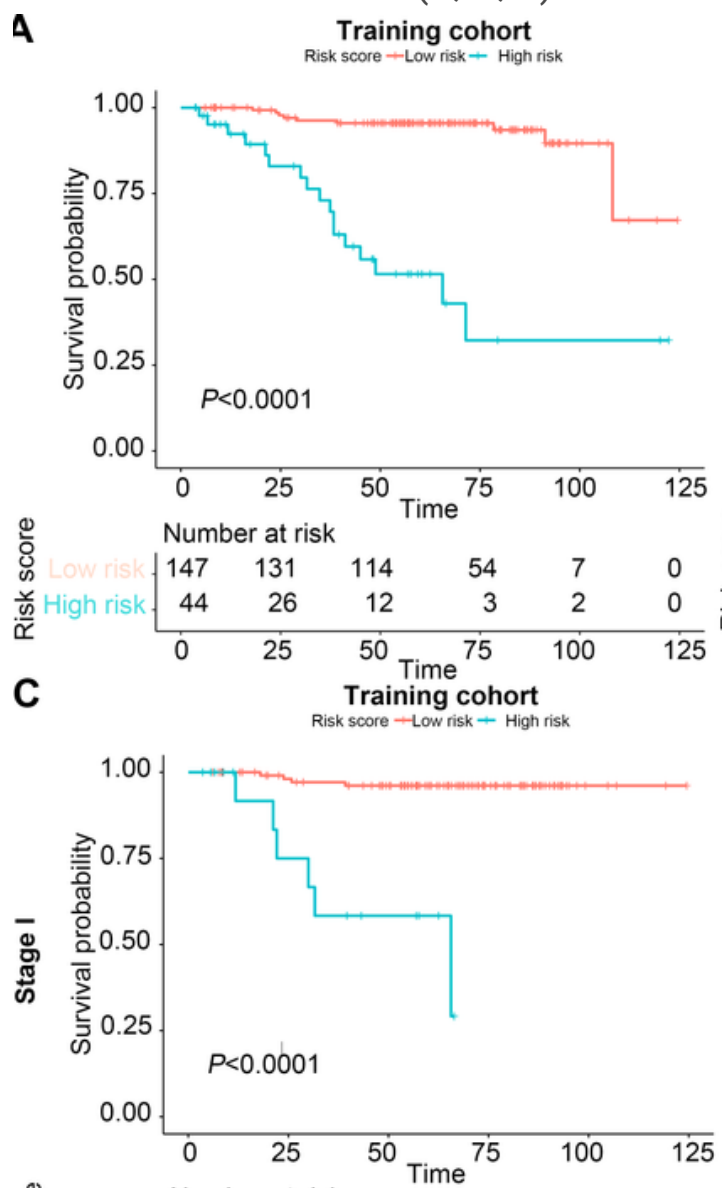

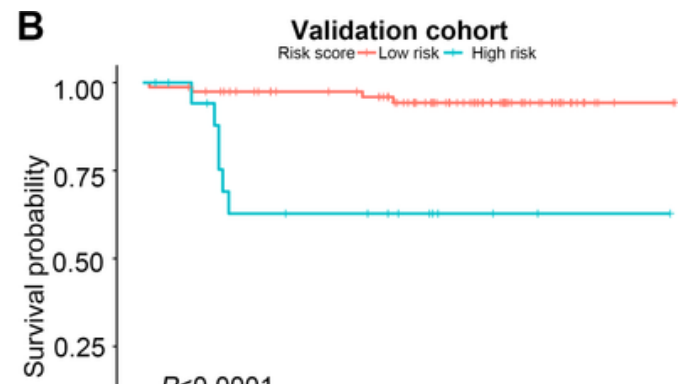

$P<0.0001$
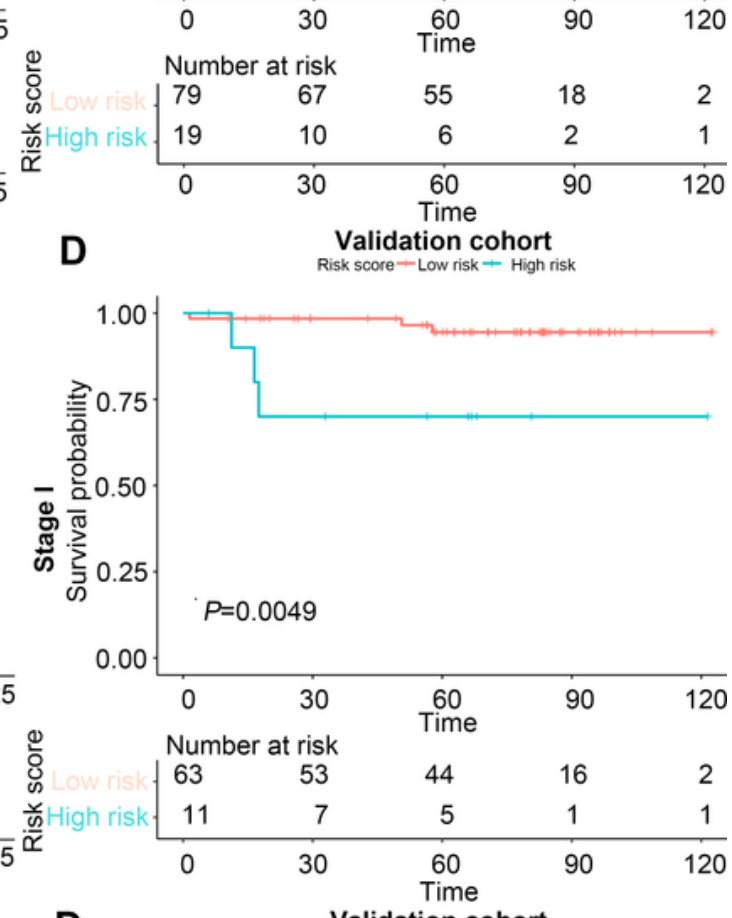

C
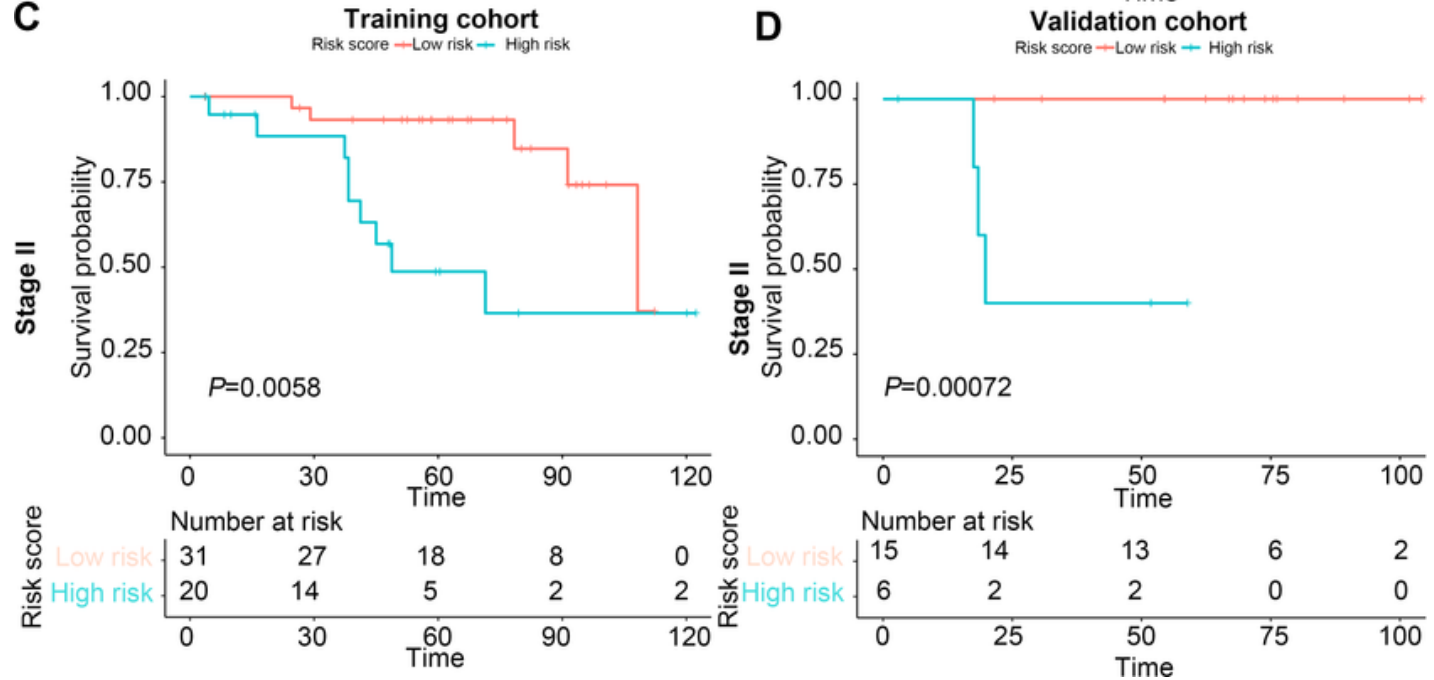

Figure 5

Graphs showing the results of Kaplan-Meier curves for all two groups based on the predictors from the nomogram model. (A-C) Graphs showing the results of Kaplan-Meier curves for all two groups based on 
the predictors from the nomogram model in all patients, stage I and stage II of training cohort $(A, C, E)$ and validation cohort $(B, D, F)$.

\section{Supplementary Files}

This is a list of supplementary files associated with this preprint. Click to download.

- SupplementaryFigure2.tif

- SupplementaryFigure2.tif

- SupplementaryFigure1.tif

- SupplementaryFigure1.tif

- SupplementaryFigure3.tif

- SupplementaryFigure3.tif 